\title{
KARAKTERISTIK PERILAKU MEROKOK MAHASISWA UNIVERSITAS MALIKUSSALEH 2019
}

\author{
Harvina Sawitri ${ }^{1}$, Fury Maulina ${ }^{1}$, Radhika Kharima Dwi Aqsa ${ }^{2}$ \\ ${ }^{1}$ Bagian Ilmu Kesehatan Masyarakat, Fakultas Kedokteran, Universitas Malikussaleh \\ ${ }^{2}$ Mahasiswa Program Studi Profesi Dokter, Fakultas Kedokteran, Universitas Malikussaleh \\ Corresponding Author : fury.maulina@unimal.ac.id
}

\begin{abstract}
Abstrak
Konsumsi rokok dikalangan remaja dan mahasiswa meningkat setiap tahunnya. Data The Tobacco Atlas menyebutkan Indonesia memiliki jumlah perokok remaja pria terbesar (66\%). Penelitian ini bertujuan untuk mengidentifikasi karakteristik serta faktor yang mempengaruhi perilaku merokok pada mahasiswa pria di Universitas Malikussaleh. Penelitian ini merupakan studi deskriptif dengan desain cross sectional. Teknik pengambilan sampel menggunakan quota sampling dengan jumlah sampel 192 orang yang telah memenuhi kriteria inklusi dan eksklusi. Data dianalisis secara univariat. Hasil penelitian didapatkan bahwa $71,4 \%$ responden berusia $20-24$ tahun dan $28,5 \%$ berusia $16-19$ tahun. Sementara $62,5 \%$ responden menghabiskan $1-10$ batang rokok per hari, 28,6\% mengkonsumsi rokok 11-20 batang per hari, 5,2\% mengkonsumsi 21-30 batang rokok per hari dan 3,6\% mengkonsumsi $>30$ batang rokok per hari. Lamanya responden segera merokok setelah bangun tidur adalah $>60$ menit sebanyak 53,6\%, 31-60 menit sebanyak 19,8\%, 6-30 menit sebesar 12\% dan dalam 5 menit sebesar $14,6 \%$. Faktor yang mempengaruhi perilaku merokok dari persentase tertinggi adalah faktor kesenangan $(55,7 \%)$, stress $(51,6 \%)$, stimulasi $(37,5 \%)$, pegangan (37\%), sosial (35,4\%), kebiasaan (31,3\%) dan craving $(28,6 \%)$. Kesimpulannya sebagian besar responden adalah berusia 20-24 tahun dengan sebagian besar konsumsi rokok 1-10 batang per hari serta lebih dari setengah responden mengkonsumsi rokok lebih dari 60 menit setelah bangun tidur dengan faktor yang paling mempengaruhi perilaku merokok adalah faktor kesenangan dan stres.
\end{abstract}

Kata kunci: merokok, perilaku, mahasiswa, Universitas-Malikussaleh

\begin{abstract}
Cigarette consumption among adolescents and students increase every year. Data from The Tobacco Atlas states that Indonesia has the largest number of male teenage smokers $(66 \%)$. This study aimed to identify the characteristics and the factors which influence smoking behavior among male students at Universitas Malikussaleh. The research used a descriptive study with cross sectional design. The sampling technique used quota sampling for 192 students who have met the
\end{abstract}


inclusion and exclusion criteria. Data were analyzed by univariate analysis. The results showed that $71.4 \%$ of respondents aged $20-24$ years and $28.5 \%$ aged $16-19$ years. Meanwhile, $62.5 \%$ of respondents consumed 1-10 cigarettes per day, $28.6 \%$ consumed 11-20 cigarettes per day, 5.2\% consumed 21-30 cigarettes per day and $3.6 \%$ consumed $>30$ cigarettes per day. The duration of the respondent immediately smoking after woke up $>60$ minutes was 53.6\%, 31-60 minutes was $19.8 \%$, 6-30 minutes was $12 \%$ and in 5 minutes after woke up was $14.6 \%$. The factors which influence smoking behavior from the highest percentage are pleasurable relaxation $(55.7 \%)$, stress $(51.6 \%)$, stimulation $(37.5 \%)$, crutch $(37 \%)$, social $(35.4 \%)$, habit $(31.3 \%)$ and craving $(28.6 \%)$. In conclusion, the majority of respondents were aged 20-24 years with predominantly of cigarettes consumption were 1-10 cigarettes per day and more than half of respondents consuming cigarettes more than 60 minutes after woke up with the most influence smoking behavior were pleasurable relaxation and stress factors.

Keywords: smoking, behavior, students, Universitas-Malikussaleh 


\section{PENDAHULUAN}

Data The Tobacco Atlas menyebutkan Indonesia memiliki jumlah perokok remaja pria (usia 15 tahun ke atas) terbesar yaitu sebanyak 66\% laki-laki. Selanjutnya Rusia berada di peringkat kedua dengan 60\%, kemudian disusul oleh China (53\%), Filipina (48\%), Vietnam (47\%), Malaysia (44\%), India (24\%), dan Brazil (22\%) (1). Badan Litbang Kementerian Kesehatan bersama dengan World Health Organization telah melakukan survei berbasis sekolah bagi pelajar SMP dan SMA tahun 2015 menyatakan persentase peserta didik yang merokok dalam 30 hari terakhir sebesar $22 \%$ pada laki-laki dan $1.6 \%$ pada perempuan dengan persentase total adalah $11.6 \%$ (2). Data menunjukkan bahwa konsumsi rokok sebanyak 21-30 batang per hari ditemukan di Provinsi Aceh. Sementara untuk konsumsi rokok lebih dari 30 batang per hari, Provinsi Aceh menempati posisi ketiga (5,4\%) setelah Bangka Belitung (16,2\%) dan Kalimantan Selatan (7,9\%) (3). Tingginya persentase ini didorong oleh adanya faktor yang mencetuskan seseorang untuk merokok. Perilaku merokok merupakan suatu aktifitas yang dilakukan akibat adanya sejumlah faktor yang sangat mempengaruhinya. Faktorfaktor yang dapat memengaruhi perilaku merokok antara lain adalah teman sebaya, teman dekat, kelompok sosial yang lebih besar, gank, dan hubungan sosial. Faktor lain yang mempengaruhi perilaku merokok adalah jenis kelamin, usia, pengalaman, pengetahuan, dan sikap individu (4).

Tujuan penelitian ini adalah untuk mengetahui gambaran karakteristik perokok berdasarkan usia, jumlah rokok perhari, dan jangka waktu merokok setelah bangun tidur serta mengidentifikasi faktor yang memicu perilaku merokok pada mahasiswa.

\section{METODE}

Penelitian ini adalah penelitian deskriptif dengan desain cross sectional. Penelitian dilakukan pada Fakultas Ekonomi, Hukum, Ilmu Sosial dan Ilmu Politik, Keguruan dan Ilmu Pendidikan, Pertanian, dan Teknik di Universitas Malikussaleh. Populasi dalam penelitian ini adalah seluruh mahasiswa Universitas Malikussaleh yang merokok. Kriteria inklusinya adalah: a) mahasiswa dengan 
status aktif; b) jenis kelamin laki-laki; c) responden telah merokok minimal 1 tahun; dan d) merokok minimal satu batang per hari. Sementara kriteria eksklusinya adalah responden tidak hadir saat dilakukan pengambilan data penelitian. Jumlah sampel dalam penelitian mengikuti formula oleh Slovin sehingga diperoleh jumlah sampel adalah 192 orang. Teknik pengambilan sampel dilakukan secara quota sampling sehingga diperoleh 32 orang mahasiswa setiap fakultas.

Variabel pada penelitian ini adalah: a) usia; b) jumlah rokok per hari; c) jangka waktu merokok setelah bangun tidur; dan d) faktor yang mempengaruhi perilaku merokok. Skala ukur usia, jumlah rokok per hari dan jangka waktu merokok setelah bangun tidur adalah skala ordinal dan skala ukur pada variabel faktor yang mempengaruhi perilaku merokok adalah nominal.

Instrumen yang digunakan dalam penelitian ini adalah kuesioner. Perilaku merokok diukur dengan menggunakan kuesioner Horn yang terdiri dari 21 pertanyaan dengan likert-scale ("selalu" diberi skor 5, "sering" diberi skor 4, "kadang" diberi skor 3, "jarang" diberi skor 2 dan "tidak pernah" diberi skor 1). Skor $\geq 10$ mengindikasikan suatu faktor penting yang mempengaruhi perilaku merokok individu. Data primer yang diperoleh selanjutnya melalui proses editing, coding, cleaning dan tabulating. Analisis dilakukan secara univariat.

\section{HASIL PENELITIAN}

\section{Karakteristik Responden}

Distribusi frekuensi umur, jumlah rokok per hari, dan jangka waktu merokok setelah bangun tidur pada mahasiswa Universitas Malikussaleh ditunjukkan pada tabel 1 . 
Tabel 1 Distribusi karakteristik mahasiswa Universitas Malikussaleh (n=192)

\begin{tabular}{llcc}
\hline & Karakteristik & n & $\begin{array}{c}\text { Persentase } \\
(\%)\end{array}$ \\
\hline Usia & $16-19$ tahun & 55 & 28,6 \\
& $20-24$ tahun & 137 & 71,4 \\
Jumlah rokok per hari & $1-10$ batang & 120 & 62,5 \\
& $11-20$ batang & 55 & 28,6 \\
& $21-30$ batang & 10 & 5,2 \\
Jangka waktu merokok setelah bangun & $>30$ batang & 7 & 3,6 \\
tidur & $>60$ menit & 103 & 53,6 \\
& & & \\
& $31-60$ menit & 38 & 19,8 \\
& $6-30$ menit & 23 & 12,0 \\
& 5 menit & 28 & 14,6 \\
\hline
\end{tabular}

(Sumber: Data Primer, 2019)

Data menunjukkan bahwa sebagian besar responden berusia 20-24 tahun, mengkonsumsi rokok 1-10 batang per hari dan mengonsumsi rokok $>60$ menit setelah bangun tidur.

\section{Perilaku Merokok}

Tabel 2 Faktor perilaku merokok mahasiswa Universitas Malikussaleh

\begin{tabular}{lccc}
\hline \multicolumn{1}{c}{ Faktor perilaku merokok } & Jumlah & Persentase (\%) \\
\hline Stimulasi & Tidak & 120 & 62,5 \\
\multirow{2}{*}{ Kesenangan } & Ya & 72 & 37,5 \\
& Tidak & & 44,3 \\
Craving & Ya & 85 & 55,7 \\
& Tidak & 107 & 71,4 \\
Pegangan & Ya & 137 & 28,6 \\
& Tidak & 55 & 63,0 \\
Kebiasaan & Ya & & 37,0 \\
& Tidak & 121 & 68,8 \\
Stres & Ya & 71 & 31,3 \\
& Tidak & 132 & 48,4 \\
Sosial & Ya & 60 & 51,6 \\
& Tidak & 93 & 64,6 \\
\hline
\end{tabular}


Berdasarkan tabel 2 diperoleh bahwa faktor perilaku paling besar bagi seseorang untuk merokok adalah Kesenangan (55,7\%) dan Stres $(51,6 \%)$. Sedangkan faktor perilaku paling kecil adalah Craving $(28,6 \%)$.

\section{PEMBAHASAN}

Hasil penelitian karakteristik usia data dari 192 responden pada mahasiswa di Universitas Malikussaleh didapatkan kelompok usia 20-24 tahun merupakan kelompok usia terbanyak dengan jumlah 137 responden $(71,4 \%)$, diketahui bahwa hal tersebut merupakan usia mahasiswa dengan kematangan dalam mengambil keputusan kesenangannya. Didapatkan bahwa lebih banyak mahasiswa yang mengkonsumsi rokok 1-10 batang per hari yaitu sejumlah 120 responden $(62,5 \%)$ dan diketahui bahwa sebagian besar responden tidak menjadikan rokok sebagai kebutuhan sehingga responden mengkonsumsi rokok dengan jumlah yang sedikit hal ini menjadikan sebagian besar responden merupakan perokok ringan. Dari hasil penelitian didapatkan responden dengan jangka waktu konsumsi rokok $>60$ menit setelah bangun tidur sebanyak 103 responden $(53,6 \%)$ diketahui bahwa sebagian besar responden mengaku bahwa tidak memilih rokok sebagai hal pertama yang dicari dan dikonsumsi setelah bangun tidur, sebagian besar responden hanya akan merokok setelah melakukan berbagai kegiatan rutin bahkan jika telah berada dikampus.

Faktor perilaku merokok diukur menggunakan kuesioner Horn dengan 21 pertanyaan penilaian akhir kuesioner dikelompokkan menjadi 7 bagian yaitu stimulasi, kesenangan, craving, pegangan, kebiasaan, stress dan social. Temuan dalam penelitian ini menunjukkan bahwa faktor kesenangan dan stres menjadi alasan terbanyak pada mahasiswa yang mengindikasikan perilaku merokok,

Stres merupakan suatu kondisi fisik dan psikis seseorang yang tidak dapat berfungsi secara normal. Stres sudah menjadi bagian yang tidak dapat dihindari dalam kehidupan dalam lingkungan sekolah, kerja, keluarga, atau dimanapun seseorang dapat mengalami stres. Stres juga dapat menimpa siapapun terkhusus pada remaja dalam lingkungan akademik stres merupakan pengalaman yang paling sering terjadi (7). Stres merupakan hal yang paling sering terjadi pada 
lingkungan akademik khususnya oleh para siswa baik yang ditingkat sekolah maupun perguruan tinggi, disebabkan banyaknya tuntutan yang harus dihadapi seperti ujian dan tugas. Beberapa peneliti menemukan bahwa seorang yang mengalami stres cenderung mengalami penurunan dalam akademik (5). Stres meliputi perubahan kondisi psikis, emosional, serta psikologis (6). Akibat dari stres, tubuh menerima rangsangan secara alami akan mengaktifkan reaksi flight or fight sebab adanya kondisi yang berpotensi mengancam tubuh (7).

Stres yang tidak mampu dikendalikan dan diatasi oleh individu akan memunculkan dampak negative kognitif, fisiologis dan perilaku. Pada mahasiswa, dampak negatif secara kognitif antara lain sulit berkonsentrasi, sulit mengingat pelajaran, dan sulit memahami pelajaran. Dampak negatif secara emosional antara lain sulit memotivasi diri, munculnya perasaan cemas, sedih, kemarahan, frustrasi, dan efek negatif lainnya. Dampak negatif secara fisiologis antara lain gangguan kesehatan, daya tahan tubuh yang menurun terhadap penyakit, sering pusing, badan terasa lesu, lemah, dan insomnia. Penyebab stres pada mahasiswa tersebut berbeda antara satu individu dengan yang lain. Faktor-faktor yang dapat menyebabkan stress dapat dibagi atas faktor internal dan faktor eksternal. Faktor internal yang berasal dari dalam diri individu mahasiswa sendiri misalnya kondisi fisik, motivasi, dan tipe kepribadian dari mahasiswa itu sendiri. Factor eksternal biasanya berasal dari luar individu seperti keluarga, pekerjaan, fasilitas, lingkungan, dosen dan lain-lain (8).

Penelitian yang dilakukan di Fakultas Teknik Universitas Sam Ratulangi tahun 2017, Manado tentang hubungan antara tingkat stres dengan perilaku merokok, didapatkan hasil yang signifikan antara tingkat stres dengan perilaku merokok dimana tingkat stres mempengaruhi perilaku merokok tiap individu perokok. Semakin tinggi tingkat stres seseorang, perilaku merokoknya semakin berat dengan presentase sebanyak 37,7\%, hal ini dikarenakan individu ingin mengalihkan stresnya ke sesuatu yang lain dalam hal ini perilaku merokok, mereka berasumsi bahwa rokok dapat membuat rileks dan sejenak melupakan stres yang mereka alami, namun dalam penelitian ini didapati juga tingkat stres sedang dengan perilaku merokok berat dengan presentasi 1,6\% atau sebanyak 1 
responden hal ini dapat diakibatkan perilaku merokok individu yang sudah menjadi rutinitas atau perilaku merokok yang tetap dilakukan ada atau tidak adanya stress (9).

Hasil yang sama juga didapatkan pada penelitian yang dilakukan di Undip tahun 2012, Sebagian besar mahasiswa menyatakan bahwa alasan pertama kali merokok adalah berasal dari teman sebaya yang menjadikannya penasaran ingin mencoba untuk merokok. Setelah merasa terbiasa merokok, mereka sudah masuk dalam kondisi ketagihan dengan anggapan bahwa dengan merokok dapat merubah suasana hati dan mengurangi rasa stres akibat beban kuliah dan praktek di lapangan(10).

Studi yang dilakukan di Kediri menunjukkan hal yang serupa, bahwa ada pengaruh faktor psikologi terhadap perilaku merokok pada mahasiswa laki laki di asrama putra STIKES RS Baptis Kediri. Merokok dapat menjadi sebuah cara bagi remaja agar mereka tampak bebas dan dewasa saat mereka menyesuaikan diri dengan teman-teman sebayanya yang merokok, tekanan- tekanan teman sebaya, penampilan diri, sifat ingin tahu, stres, kebosanan, ingin kelihatan gagah, dan sifat suka menentang, merupakan hal-hal yang dapat berkontribusi dimulainya merokok. Ada beberapa alasan psikologi yang menyebabkan seseorang merokok, yaitu demi relaksasi atau ketenagan, serta mengurangi kecemasan atau ketegangan. Pada kebanyakan perokok, ikatan psikologis dengan rokok dikarenakan adanya kebutuhan untuk mengatasi diri sendiri secara mudah dan efektif. Rokok dibutuhkan sebagai alat keseimbangan (11).

\section{KESIMPULAN}

1. Sebagian besar responden berusia 20-24 tahun dengan sebagian besar konsumsi rokok 1-10 batang per hari serta lebih dari setengah responden mengkonsumsi rokok lebih dari 60 menit setelah bangun tidur

2. Faktor stres dan kesenangan merupakan faktor yang paling mempengaruhi perilaku merokok. 


\section{REFERENSI}

1. Amalia MN. Analisis Pengaruh Konsumsi Rokok Terhadap Produktivitas Tenaga Kerja di Indonesia. Yogyakarta; 2017.

2. Badan Litbang Kementerian Kesehatan. Perilaku Berisiko Kesehatan pada Pelajar SMP dan SMA di Indonesia [Internet]. 2017 [cited 2020 Jun 23]. Available from: http://www.pusat3.litbang.kemkes.go.id/news-175perilaku-berisiko-kesehatan-pada-pelajar-smp-dan-sma-di-indonesia.html

3. Badan Penelitian dan Pengembangan Kesehatan Kementerian Kesehatan RI. Riset Kesehatan Dasar. Jakarta; 2010.

4. Wijayanti E, Dewi C, Rifqatussa'adah. Faktor-faktor yang Berhubungan dengan Perilaku Merokok pada Factors Associated with Teenager ' $\mathrm{s}$ Smoking Behavior at. Glob Med Heal Commun. 2017;5(November):1948.

5. Talib N, Urrehman Z. Academic performance and perceived stress among university students. Educ Res Rev. 2012;7(5):127-32.

6. Carr, D., \& Umberson D. The social psychology of stress, health, and coping. In DeLameter, J. \& Ward, A. (Eds.). Handbook of Social Psychology. Netherlands: Springer; 2013. 465-487 p.

7. Lyon BL. Stress, coping, and health. In Rice, H. V. (Eds.) Handbook of stress, coping and health: Implications for nursing research, theory, and practice. USA: Sage Publication; 2012. 3-23 p.

8. Heiman, Kariv. Task-Oriented versus Emotion-Oriented Coping Strategies: The Case of College Students. Coll Stud J. 2005;39(1):72-89.

9. Bawuna N, Rottie J, Onibala F. Hubungan Antara Tingkat Stres Dengan Perilaku Merokok Pada Mahasiswa Fakultas Teknik Universitas Sam Ratulangi. J Keperawatan UNSRAT. 2017;5(2).

10. Kurniati A, Udiyon A, Ari Udiyon Lintang Dian Saraswati. Gambaran Kebiasaan Merokok dengan Profil Tekanan Darah Pada Mahasiswa Perokok Laki-laki Usia 18-22 Tahun (Studi Kasus di Fakultas Teknik Jurusan Geologi Universitas Diponegoro Semarang). J Kesehat Masy. 2012;1(2):251-61.

11. Febrijanto Y, Fikriyah S. Factors That Influence the Smoking Behaviour of Male Students in Dormitories. J Penelit STIKES Kediri. 2012;5(1):99109-109. 